\title{
2 Formal social protection and informal workers in Kenya and Tanzania
}

\author{
From residual towards universal \\ models?
}

\author{
Nina Torm, Godbertha Kinyondo, Winnie \\ Mitullah and Lone Riisgaard
}

\section{Introduction}

In Kenya, following independence in 1963, the government has with its national development plans supported social protection as a key response to poverty through targeting the most vulnerable and desperate in society. However, the actual provision of social protection has taken many different forms and has generally been characterized by fragmented interventions, due in part to the various international agencies involved. In Tanzania, which gained independence in 1961 and has experienced a different economic history compared with Kenya, social protection has also consisted of fragmented efforts by a variety of actors, including international donors. As such, there is a lack of an overarching social protection policy framework that establishes clear institutional roles and responsibilities and lays out a concrete implementation plan from the central to local government levels. This compounded with a lack of financial resources and capacity both within government and civil society has until recently resulted in an inadequate provision of social protection for the general population.

However, in both countries, we are seeing a move towards more unified social protection approaches including the extension of coverage to informal workers. As already outlined in Chapter 1 , this is partly a result of international recommendations, including the ILO's National Social Protection Floors (2012) and frameworks like the Sustainable Development Goals (SDG) putting pressure on African governments to expand the provision of social protection. At the regional level, social protection policy in both Kenya and Tanzania is governed by the African Union Social Policy framework which was endorsed by all Heads of States in 2009, and the wide-ranging provisions on the harmonization and coordination of social security that guide the actions of the East African Community (EAC) Partner States. For the purpose of this chapter, we will not go into detail on the global and regional governance of social protection yet concentrate on the relevant national frameworks and their implication for informal workers in Kenya and Tanzania, respectively. The rest of the chapter is composed of a section on Kenya's social protection framework with sub-sections focusing on the 


\section{Nina Torm et al.}

National Social Security Fund (NSSF) and National Health Insurance Fund (NHIF), followed by a similar section on Tanzania zooming in on NSSF and NHIF/Community Health Fund (CHF). A brief sum-up is provided at the end of the chapter.

\section{Kenya's social protection framework}

In 2006, under the auspices of the African Union, the government of Kenya began the process of formulating a national social protection framework in consultation with representatives from government ministries, non-state actors including the private sector, community groups, voluntary organizations, and development partners, whilst also exploring international best practices in the provision and financing of social protection. The resulting National Social Protection Policy (NSPP, 2011) outlines how the consultations identified several key barriers that were preventing people from accessing social protection services, including stigma and discrimination on account of gender, disability, age, nationality, area of residence, and poor wellbeing. ${ }^{1}$ Yet, among these barriers to accessing social protection services, informality is not explicitly spelled out.

The NSPP defines social protection as follows:

Policies and actions, including legislative measures that enhance the capability of and opportunities for the poor and vulnerable to improve and sustain their lives, livelihoods, and welfare, that enable income-earners and their dependants to maintain a reasonable level of income through decent work, and that ensures access to affordable healthcare, social security, and social assistance.

(NSPP, 2011, p. v)

The NSPP is consistent with Kenya's 2010 constitution which in article 43 expressly guarantees all Kenyans their economic, social, and cultural (ESC) rights including basic rights to health, education, food, and decent livelihoods. It explicitly asserts the right "of every person... to social security" and binds the State in Article 43(3) to "provide appropriate social security to persons who are unable to support themselves and their dependants". ${ }^{2}$ The right to social security, in both the wide and narrow sense, is closely interlinked with other social protection rights including the right to healthcare services, equality and freedom from discrimination, human dignity, freedom of movement and residence, reasonable working conditions, fair administrative actions, access to justice, and the resolution of disputes in a fair manner and through public hearing before a court or independent and impartial tribunal or body (NSPP, 2011, p. 1). As such, social protection is geared towards improving human capabilities through social assistance (cash transfer programmes) and/ or social security (pensions and health insurance). In terms of the latter and in relation to informality, the NSPP states that 
The Government, working with all other stakeholders, shall:

i Strengthen the existing social security regime and establish comprehensive social security arrangements that will extend legal coverage to all workers, whether in the formal or informal sectors, and their dependants (NSPP, 2011, p. vi).

ii Undertake research into and consider viable options for extending coverage to those who work informally and their dependants in consultation with key stakeholders, including those in affected communities and sectors (NSPP, 2011, p. vii).

Interestingly, in the first paragraph, the wording informal sector gives the impression of a limited segment of informal workers, whilst the second paragraph refers to those who work informally which is a broader category of workers in the informal economy. Regardless of the subject, the cited objectives on extending social protection measures to the informal are clearly in line with the ILO agenda of "formalizing the informal" (ILO, 2015).

The NSPP is also in line with Kenya's Vision 2030 which aims to provide a "high quality of life for all its citizens by the year 2030". Built on three pillars economic, social, and political, the social pillar of the Vision seeks to build "a just and cohesive society with social equity in a clean and secure environment". Vision 2030 is the national long-term development policy which has provided an impetus for the government to increase investment in social protection to the levels invested in comparable countries. For the first five-year period (2008-2012), the Vision's goal was “to increase opportunities all-round among women, youth, and all disadvantaged groups", and one of the actions proposed to achieve this was the establishment of a consolidated Social Protection Fund administered by the National Social Protection Council (NSPC). Whilst there has been limited progress in reforming the contributory schemes (KSPSR, 2017), progress has been made along other parameters, including the senior citizens "Inua Jamii 70 years and above" programme which was introduced in January 2018, representing Kenya's first universal social protection programme, guaranteeing a minimum pension to all older persons aged above 70 years. The scheme is funded by the government and has been rolled out to around 533,000 senior citizens, expanding the Older Persons Cash Transfer programme (OPCT), which was targeted to poor and vulnerable households. If "Inua Jamii 70 years and above" attains full coverage, around 840,000 persons will be able to access the scheme and about 68,000 people aged 65-69 years will continue on the OPCT. In total, it is expected that the share of those aged 65 years and over who receive an old age pension should increase to 77 percent from around 31 percent (KSPSR, 2017). Aside from being a response to the limitations of targeting, this more universalistic approach is portrayed as an effective solution to offering pensions for the informal economy.

The programme is expected to address many of the current challenges with pension coverage some of which are outlined later on in the NSSF section. 


\section{Nina Torm et al.}

With regard to the health insurance pillar of social protection, the NSPP does not explicitly mention informal workers but states that the government, in collaboration with partners, shall:

i Re-establish the NHIF as a fully-fledged comprehensive national health insurance scheme, which covers all Kenyans, and to which those who can afford it must contribute (NSPP, 2011, p. vii).

ii Establish a framework for enabling those who are not able to contribute to access a core package of essential health services, including maternity care and treatment for HIV/AIDS and related diseases (NSPP, 2011, p. vii).

Following the NSPP, there have been two Social Protection Sector Reviews (KSPSR, 2012, 2017), and during this period, both the NSSF and the NHIF have opened up to informal workers. The most recent KSPSR (2017) lists the progress made in this regard, and the key dimensions are summarized in Table 2.1. ${ }^{3}$

From the brief overview, it is thus clear that there has been limited progress in terms of extending both pensions and health insurance to informal workers, and as indicated earlier, the underlying discourse remains one of formalizing the informal. More specifically, when relating the recommendations from the KSPSR (2012) to the different trajectories on social protection, as outlined in Chapter 1,

Table 2.1 Summary of progress in implementing key recommendations from the KSPSR, 2012, related to the informal economy

\begin{tabular}{|c|c|}
\hline Proposal & Progress \\
\hline $\begin{array}{l}\text { To strengthen the existing social security } \\
\text { regime and establish comprehensive } \\
\text { social security arrangements that will } \\
\text { extend legal coverage to all workers, } \\
\text { whether in the formal or informal } \\
\text { sectors, and their dependants. }\end{array}$ & $\begin{array}{l}\text { Limited progress. However, the universal } \\
\text { Inua Jamii Senior Citizens' programme } \\
\text { is considered as a more effective tool } \\
\text { for offering workers in both formal } \\
\text { and informal sectors a pension. It will } \\
\text { need to be established in law for it to be } \\
\text { considered as a legal coverage. }\end{array}$ \\
\hline $\begin{array}{l}\text { Determine the most appropriate role to } \\
\text { be played by occupational schemes in } \\
\text { extending social security coverage to } \\
\text { those who can contribute to their own } \\
\text { post-retirement welfare and security and } \\
\text { risk mitigation. }\end{array}$ & $\begin{array}{l}\text { There has been some expansion of } \\
\text { contributory retirement schemes for } \\
\text { those in the informal economy, but } \\
\text { they still provide only lump sums so act } \\
\text { more like savings schemes (see Box } 2.1 \\
\text { on the Mbao Pension Plan). }\end{array}$ \\
\hline $\begin{array}{l}\text { A national social health insurance scheme } \\
\text { will be initiated that will protect both } \\
\text { formal and informal sector workers } \\
\text { as well as the unemployed from the } \\
\text { economic liability of health shocks. }\end{array}$ & $\begin{array}{l}\text { Limited progress. The focus is still } \\
\text { on the NHIF, and a broader health } \\
\text { insurance scheme has not been formally } \\
\text { introduced. However, through the } \\
\text { Universal Health Coverage (UHC) } \\
\text { programme in four counties (Kisumu, } \\
\text { Nyeri, Isiolo, and Machakos) the } \\
\text { government is working on expanding } \\
\text { social protection to informal workers. }\end{array}$ \\
\hline
\end{tabular}

Source: Adapted from KSPSR (2017). 
they can be viewed as being located somewhere between the left (beginning) of the continuum towards the middle of the continuum. Whilst the proposal on contributory retirement schemes for risk mitigation and health schemes to address the economic liability of shocks are more in line with the residual approach of, for instance, the World Bank, the recommendation to "extend legal coverage to all workers, whether in the formal or informal sectors, and their dependants" resonates more with the perception of social protection as a right in accordance with universal models. In that sense, there is still very limited recognition of the broader transformative role of social protection as emphasized in the Devereux and Sabates-Wheeler (2004) framework, not to mention the plurality of informal social protection measures as revealed throughout this book. This disconnect between the official social protection policy stance, its implementation and the reality on the ground is where our research is situated. In what follows, and with the purpose of providing the context for the subsequent chapters, we provide an account of the two main public insurance schemes in Kenya and how they relate to informal workers.

\section{National Social Security Fund}

When the NSSF was established through an Act of Parliament in 1965, it only covered men that were formally employed; yet, in 1977, the scheme opened up to women and with the 2013 NSSF Act coverage was extended to workers in the informal economy. Today, the NSSF covers all categories of employers and workers and is a mandatory retirement scheme whose main objective is to provide basic financial security benefits to Kenyans in both the formal and informal sectors (NSPP, 2011, p. 12). The NSSF has two tiers of contribution, namely the provident fund and the pension fund, and whilst the latter is obligatory for all formal employees from the age of $18-60$, the former is voluntary and caters for selfemployed and unemployed workers who fail to meet the minimum provisions. Prior to 2013 contributions amounted to 5 percent of earnings by each of the employee and employer, subject to a cap on earnings of Kenyan Shillings (KES) 400 (USD 4) per month. Currently, contributions, which depend on minimum wages, amount to 6 percent payable by each of the employee and employer with the 'cap' having increased to KES 2,160 per month (USD 21) (KSPSR, 2017). In return, members receive benefits upon turning 60 years. Although NSSF annual contributions and annual benefits increased by 5.2 percent and 2.6 percent, respectively, in 2018 (KNBS, 2019), the low monetary ceiling on contributions means that the current level of benefits is generally considered inadequate.

In terms of coverage, during 2014-2018, the number of registered employers and employees increased by 6.8 percent and 3.0 percent to 143,300 and $4,068,400$, respectively. During the same period, the number of registered women employees increased by 4.8 percent compared to 2.4 percent growth recorded for men employees (KNBS, 2019). Despite such increases and the fact that the NSSF has 60 branches and is accessible in each of the 47 counties through 'Huduma Centres', effective coverage remains low. In terms of active members, it 
is estimated that, for formal and informal workers, only 15 percent of those aged 18-65 years have an employer contributing to NSSF pensions (KSPSR, 2017), which is nevertheless an increase from 2011 (NSPP, 2011, p. 12). The low level of benefits could be a factor dissuading especially informal workers from joining the scheme. Moreover, as discussed throughout this book, low enrolment of informal workers is attributed to challenges such as low wages, lack of contracts, high poverty, little awareness of NSSF, and the bureaucratic nature of the scheme. In addition, scant information on informal economy workers makes it difficult for government programmes to prioritize them; yet, in order to extend coverage further, the NSSF is working with informal worker organizations, examples of which are provided in the subsequent chapters of this edited volume.

Since 2013, NSSF members have the option of 'contracting out' of the mandated pension component if the individual worker has a pension through an alternative scheme. An example is the 'Mbao' scheme (Box 2.1) which is an initiative to extend private pensions to the informal sector; however, in line with existing literature (Kabare, 2018), our research shows that very few informal workers subscribe to Mbao. Moreover, it appears that the scheme is not well understood. For instance, the phrase " "tupa' (throw) twenty shillings" which was used by some workers when talking about the scheme revealed the suspicion of those throwing the 20 shillings. ${ }^{4}$ Observations also revealed that the Mbao

\section{Box 2.1 The 'Mbao' scheme: a flagship initiative of the Retirement Benefits Authority (RBA)}

The Mbao Pension Plan was established in 2009 by the Kenya National Federation of Jua Kali Associations as a voluntary retirement savings scheme, geared towards supporting citizens engaged in the informal sector who are not accessing any social security support, although it is open to any citizen who would like to join. It is registered as a retirement benefit scheme, yet is managed privately in the same way as most of the 'normal' occupational schemes operating in the country. Mbao offers members to easily accumulate a low level of regular savings at minimal cost - typically though the money transfer schemes operated by the mobile phone companies. In 2016, the total recorded membership was about 99,000, with an accumulated fund of about KES 110 million. Thus, while the scheme membership has, until now, reached only a rather limited proportion of the target population of informal economy workers, it has grown fairly steadily. However, since contributions can be - and typically appear to be withdrawn after a required minimum period of three years, there is little evidence that Mbao will be able to contribute to old age income security. Thus, whilst being modestly attractive as a savings vehicle, it is unlikely to function as a reliable pension scheme for those working in the informal economy (KSPSR, 2017). 
scheme is 'a child without a parent', with many agencies claiming ownership including the Jua Kali Association, Kenya Commercial Bank, Kenya Retirement Benefits Authority, Eco Pension Plan, and the ILO. Thus, governance of the Mbao scheme seems not well consolidated. In January 2020, the NSSF in collaboration with the NHIF, Kenya Commercial Bank, Safaricom, and Proto Energy launched a new pension scheme for informal workers named 'Haba Haba', seeking to address the immediate and medium term needs of present and future NSSF members, initially targeting informal worker in the transport sector. The scheme gives members of the informal economy a chance to save a minimum of KES 25 (USD 0.25) a day with the option of withdrawing 50 percent of their contributions after consistently contributing for a minimum of five years. This differs from NSSF offers in the formal sector where members have to retire or attain the age of 50 years to access their savings. At the time of writing, it is, however, unclear how or whether the 'Haba Haba' scheme relates to the Mbao scheme and whether the latter still remains in operation.

\section{National Hospital Insurance Fund}

The NHIF was established in 1966 as a department under the Ministry of Health, and like NSSF, it was part of the government's efforts to cushion workers against future vulnerabilities. Although several schemes in Kenya offer healthcare, the NHIF is the primary one covering more than 90 percent of the insured population. In 1972, the NHIF extended coverage to self-employed/informal workers on a voluntary basis, and later on, outpatient coverage for both formal and informal sector workers was introduced in addition to in-patient services (NSPP, 2011, p. 13). In 2012, the NHIF established a health insurance package for informal workers providing beneficiaries with access to a range of treatments and services for a monthly premium contribution of KES 500 (USD 4.6) per family paid by the individual worker. Moreover, everyone who receives the "Inua Jamii 70 years and above" pension is also accepted as members of the NHIF, with their contributions paid by the government (KNBS, 2019). ${ }^{5}$

In terms of the number of NHIF registered members, this has increased gradually from 4.5 million in 2013/2014 to 7.7 million in 2017/2018 (KNBS, 2019) and 9 million in 2019/2020 (KII, Nairobi). ${ }^{6}$ Since the NHIF also provides for immediate family members, the total number of people benefiting was around 18.4 million in 2017, equivalent to around 39 percent of the population (KSPSR, 2017). ${ }^{7}$ The rate of membership expansion has been particularly high among informal workers who saw a 23 percent rise for the period 2013/2014 to $2017 / 2018$ compared with a formal sector increase of 4 percent (KNBS, 2019). In terms of numbers, informal workers made up around 700,000 contributing members in 2011 increasing to an estimated 2.5 million in 2015/2016 (KSPSR, 2017) and 3.2 million in 2019/2020 (KII, Nairobi). Thus, around 41 percent of total members come from the informal economy; yet, considering that there are around 14 million informal workers, the coverage gap among this group remains substantial. 
As indicated in Table 2.1, the UHC programme, which was launched at the end of 2018, presents an attempt to further expand social protection to informal workers. ${ }^{8}$ The programme was supposed to operate for one year after which a review would assess how to roll it out to the rest of the 46 counties; yet, it was extended for three months with no extra resources. During this time, 40 other counties had signed the Intergovernmental Participation Agreement (IPA) with the national government. Further commitment was made through an inter-governmental relations agreement in October 2020, with provisions for developing a UHC policy and review of the NHIF to provide for UHC, including establishment of a UHC Fund (ROK, 2020). All these commitments are in progress as the government intensifies provision of primary health care, viewed as a foundation for UHC. However, public observations indicate that the programme has been underfunded with some pilot counties not even receiving half of the budgeted amount. Moreover, even if/when the programme is rolled out country-wide, it seems likely that, given the low sustainability and predictability of informal workers' income, the majority of premium contributors will not be consistent in their payment and will likely require subsidies (Okungu \& McIntyre, 2019). In fact, the inconsistency of informal sector contributions has prompted the NHIF to put in place a two-month restriction on usage of the NHIF card for self-employed contributors to avoid people only enrolling when they are seeking service.

The research presented in this book reveals that some of the reasons for poor enrolment/inactiveness of informal workers include cost of premium, registration problems, lack of information, and informal associational cushioning. In order to better reach informal economy workers, the NHIF has started to engage them through their associations, something which will be discussed in the sector-specific chapters. Although, the number of informal economy workers that have joined the NHIF remains relatively low, the NHIF has, until now, been more successful than the NSSF.

\section{Tanzania's social protection framework}

Tanzania's Development Vision 2025, the National Social Security Policy NSPP (2003), the National Ageing Policy (2003), and the Health Sector Strategic Plan 2015-2020 all envisage social protection for every citizen in Tanzania. Towards this purpose and following the publication of the NSPP in 2003, the Tanzanian government has enacted a number of legislations to address social security issues, leading to the establishment of the Social Security Regulatory Authority (SSRA) in 2008, with the mandate to govern and regulate the pensions and health insurance schemes. In 2010, from an initial draft in 2000, Tanzania published its National Social Protection Framework (NSPF).

NSPF (the National Social Protection Framework) is part of national efforts to reduce poverty and its primary aim is to reach the most vulnerable and ensure their protection. It is also a means of building the capabilities of the 
poor to engage in production so that they become effective participants in and beneficiaries of the growth process.

(United Republic of Tanzania, 2008, p. 2)

The wording in this statement is very much along the lines of the residual risk management approach to social protection, where the latter is not seen to play a developmental role in itself, but rather, there is a general trust in the ability of the market to deliver broad economic and social progress. Following the NSPF, in 2012, the social security law (SSL) was amended, and coverage extended to "apply to any person employed in the formal or informal sector or self-employed within mainland Tanzania” (SSL, 2012, p. 50). The amended SSL also defined the informal sector as "the sector which includes workers who work informally and who do not work in terms of an employment contract or any other contract contemplated in the definition of employee" (SSL, 2012, p. 51). Initially, the 2012 SSL banned the withdrawal of benefits before retirement age; yet, after public outcry, the parliament lifted the ban later that year. However, with the passing of the Social Security Fund Act in 2018, the ban is back so as to preserve the meaning of pensions, and a member who resigns will have to wait until they reach the age of 55-60 to get their benefits. ${ }^{9}$

Despite their wording, neither the 2003 policy nor the 2010 social protection framework sufficiently addressed issues of informal workers and participation of poor households, and neither define clearly how different actors could implement social assistance programs and voluntary schemes. These shortfalls in design, implementation, coordination, monitoring, and evaluation processes for linking up and ensuring national coverage in the implementation are still under discussion. Since April 2018, a new NSPP has been proposed consisting of three pillars: social assistance, social insurance (health and pension), and voluntary schemes. ${ }^{10}$ The latter would cover associations of informal workers for instance. Whilst the revised NSPP is still to be approved, three public insurance schemes - the NSSF, the NHIF, and the CHF - are all open to informal workers and in what follows we consider the relevance and potential accessibility of each of these.

\section{National Social Security Fund}

The NSSF caters for employees in the private sector, the self-employed, foreigners employed in Mainland Tanzania, and employees in international organizations based in Mainland Tanzania. Any category of temporary employee is registrable under the NSSF, and the "The National Informal Sector Scheme" applies specifically to informal workers. The informal membership figures have varied substantially year-on-year and, in 2017/2018, registered informal worker members represented 18,631 down from 47,780 in 2014/2015 (NSSF, 2018). ${ }^{11}$ One explanation for the sharp fall in informal members is that whilst workers are initially attracted to joining the scheme in order to receive loans and other shortterm benefits, in the longer run, they drop out and/or join informal groups for the reasons discussed in the sector specific chapters. In addition to social 
security, the NSSF offers health and medical coverage, however this benefit is seemingly on hold due to the high administrative expenditure at around 22 percent of the Fund's income. In early 2018, the Public Service Social Security fund (PSSSF) was signed into Law including a Voluntary Savings Retirement Scheme (VSRS) for the employed, self-employed, informal sector workers, and all other categories of people such as farmers, fishermen, drivers, micro-traders, food venders, organized groups such as VIBINDO (an association of small businesses), Saving Associations and Credit Co-operative Societies (SACCOS), women groups, and professionals. ${ }^{12}$ Under the VSRS, contributors were eligible for pension and health insurance upon payment of TZS 20,000 per month during three consecutive months; however, the health insurance part was deemed too costly and was not renewed after the end of 2019.

Despite these openings, informal sector workers are largely excluded from the ambit of the social security legislative framework, due to a number of challenges outlined by Ackson \& Masabo (2013). First, all the schemes (except CHF) require contributions from both the employer and the employee, and workers in the informal sector may be unable to contribute "double" portions on behalf of their "non-existent" employer and themselves. Even when informal workers do have employers, in the absence of a regulatory framework, employers may be unwilling to make contributions to a social security fund because this increases their labour costs. Similarly, in cases where employer contributions are not mandated by law, informal workers may be reluctant to allow their employer to deduct contributions to the social security scheme as they would receive lower pay. Moreover, the benefits of the schemes are not deemed to be substantial enough to warrant contributions, whilst uncertainty and unreliability of income may impair informal sector membership, contributions, and qualifications for benefits. For instance, for a member to qualify for invalidity pension and maternity benefits under the NSSF, workers must have contributed for a minimum of 36 months out of which 12 months contributions must have been made within the immediate past 36 months before the occurrence of the social risk. ${ }^{13}$ Finally, workers in the informal sector are unaware of the core functions and operations of social security schemes. In order to address some of these issues, the NSSF has been providing short-term benefits to informal sector contributors as a motivating factor for them to continue their membership. For example, each year, upon satisfactory contribution from an informal sector member, the NSSF will issue that member with an appropriate asset - i.e. fuel or tyres for bodaboda workers, or cooking utensils, chairs, etc., for informal food vendors.

\section{National Health Insurance Fund and Community Health Fund}

The largest health insurance schemes are the NHIF and the CHF/iCHF. From the early 1990s, the Tanzanian government adopted reforms that changed the health financing system from free services to mixed financing; yet, health insurances were only formally introduced in 2000, as part of larger health reforms aimed at improving access to health services. By then, it was becoming 
increasingly difficult for ruling politicians to defend the inconsistency between the promise of universal access to social services heralded under African socialism and the reality of limited access (Pedersen \& Jacob, 2018). ${ }^{14}$ Whilst the NHIF was initially meant for civil servants, employees in executive agencies and government parastatals, coverage was later on extended to private-sector employees and the self-employed plus family members. Following the health-sector reforms in the early 1990s, the CHF was introduced in 1996 as part of the endeavours to make health care affordable and available to the rural population and workers in the informal sector on a voluntary basis. In 2001, the government passed the CHF Act (supported by the World Bank), formally institutionalizing it as a voluntary insurance-based hybrid scheme, administered at the district level and co-financed by the community (household) and the government. In practice, this means that the CHF members must first seek care at a dispensary or health centre in their districts which then submits the claims to the central government that then matches the collected membership fees. In 2009, the NHIF was contracted to oversee operations of the $\mathrm{CHF}$ which targets the rural informal population and its counterpart TIKA which covers the informal sector in urban areas (Mbekeani, 2009; Rwegoshora, 2016; Pedersen \& Jacob, 2018).

The CHF has encountered challenges including poor enrolment and poor health services offered to members. Since 2014, the CHF has been under replacement by an improved CHF system (iCHF), permitting members to access health services outside of their districts and providing a more comprehensive package of services. Thus, the $\mathrm{iCHF}$ was introduced as a voluntary, district-owned health insurance scheme, built on a strong partnership between the NHIF, the district councils, public and private health care facilities, and PharmAccess. By September 2016, more than 100,000 people had enrolled in the iCHF, and the aim is to enrol at least 30 percent of the population in each of the districts of the Northern Zone's Kilimanjaro, Arusha, and Manyara regions by 2021. The government has also successfully tested the $\mathrm{iCHF}$ in the regions of Dodoma, Kilimanjaro, and Mbeya. In 2019, after assuming oversight of the CHF/TIKA schemes, the Ministry of Health, Community Development, Gender, Elderly and Children (MOHCDGEC) assessed lessons learned and has taken initial steps to consolidate and rename the schemes referring now to all former $\mathrm{CHF}$ / TIKA schemes collectively as the iCHF scheme. THE MOHCDGEC has also begun to pool funds at the regional level to enable greater cross subsidization of health costs. The new standard benefit package for the $\mathrm{iCHF}$ centres on the provisions of primary care; yet, benefits are more limited than those offered by the NHIF and most private health insurance schemes. The iCHF charges a single per-beneficiary premium of TZS 40,000 (USD 20) annually in Dar es Salaam or TZS 150,000 (USD 65) per household of six and TZS 30,000 (USD 13) in all other urban areas. In rural areas, premiums range from TZS 10,000-30,000 with the latter being for a household of six, and for all locations, the government matches the contribution (Lee, Tarimo \& Dutta, 2018). The parliament is expected to pass legislation in late 2020 /early 2021 that will authorize the national rollout of $\mathrm{iCHF}$ as preparation for the Universal Health Care policy. 


\section{Nina Torm et al.}

As for the NHIF, individual households from the informal sector can voluntarily enrol for an annual premium of approximately USD 672, which is well above the $\mathrm{iCHF}$ and beyond the means of many informal workers. ${ }^{15}$ In terms of membership, the NHIF recorded an increase in their membership base from 164,708 in $2001 / 2002$ to 468,611 in $2010 / 2011$ up to around 750,000 in 2017 (Prabhakaran \& Dutta, 2017). Since up to six family members can be added to the employee's membership, this means that the total number of beneficiaries might be about 3.5 million, equivalent to around 7 percent of the population (Wang et al., 2018).

This is in line with estimates provided by Pedersen and Jacob (2018) according to whom existing insurance schemes covered approximately 22 percent of the population $(7$ percent by the NHIF, 12 percent covered by the voluntary CHF, 1 percent by private insurances, 1 percent by community-based health insurances and 1 percent by the NSSF). ${ }^{16}$ According to NHIFs own data, coverage has been steady around 7 percent of the population in the period from 2012/2013 to 2017/2018, whereas a large increase is reported for CHF for the same period (Riisgaard, 2020). Thus, as of 2018, it is estimated that around 34 percent of Tanzanians have some form of health insurance with 25 percent ( 13.5 million beneficiaries) covered by the CHF, 7 percent by the NHIF with private health insurance accounting for 2 percent (NHIF Factsheet for FY2017/18). ${ }^{17}$ This rise in CHF enrolment is also reported by other sources (Wang et al., 2018) citing an increase in the membership base from around 7.4 percent of the population in 2011 to 19.8 percent in 2015 . In actual numbers, this means that, as of June 2017, more than 2 million households were enrolled in the CHF serving over 12 million beneficiaries.

In 2015/2016, several new schemes were introduced under the NHIF attempting to broaden the uptake. This included a scheme for the elderly ('Wazee Kwanza') for children under 18 years ('Toto Afya Kadi') and for expectant mothers ('Mama na Mwana') and the NHIF mutual plan, known as the KIKOA scheme which is a health insurance scheme for groups in the informal sector e.g. VIBINDO, SACCOS, AMCOS, VIKOBA and special groups of registered entrepreneurs like motor cycle drivers (boda boda), food vendors or any other entrepreneurial group of members not less than 20 .

The KIKOA scheme extended informal sector access to the NHIF through allowing members of registered associations in the informal economy with a minimum of 20 members (who had been together for a minimum of six months) to sign up for TZS 76,800 (USD 35) annually per person. In addition, members can add up to six dependents for an additional annual fee of TZS 76,800 per head, thus substantially above the CHF cost. According to 2017/2018 figures from the NHIF, the KIKOA scheme reached 33,057 members, equivalent to 3.85 percent of the total NHIF membership. Although, in theory, such a groupbased insurance NHIF scheme seemed well-suited and affordable, it appears, from the research presented in this book, that the membership cost has been a significant burden for many. In addition, for the more insecure and weaker groups, the NHIF does not even appear to be on their radar. These findings are echoed in the literature (Mushi \& Millanzi, 2019), and many of the issues 
are similar to those of informal workers in Kenya, as seen earlier. For reasons related to adverse selection issues, the KIKOA program was terminated by NHIF towards the end of 2019, and instead, the NHIF has other models such as the bodaboda Afya (health) which costs TZS 100,000 per head.

Private institutions such as the Jubilee Insurance have previously had health insurance schemes targeting informal workers, and other smaller private-sector health insurance providers also exist, along with various informal micro-health insurance schemes provided by, for instance, churches and cooperatives mostly operating on a very small scale (Mills et al., 2012; Pedersen \& Jacob, 2018). To this should be added the myriad of different formal and informal associations which, as will be shown in later chapters, offer a one-off amount in case of health-related challenges. Given that only 3 percent of total health financing is covered by official insurance schemes (Pedersen \& Jacob, 2018) with the remainder being out of pocket, the importance of such informal health insurance schemes should not be underestimated. This is particularly relevant for poorer sections of the population as, according to Wang et al. (2018), demographic and health survey data from the period 2015-2016 shows that NHIF covers mostly the top 40 percent of the income distribution.

As in other SSA countries, the influence of international development partners in the adoption of health insurances is undeniable and largely mirrors the international trends described earlier. However, as shown by Pedersen \& Jacob (2018), major reforms (in both social assistance and in healthcare) were typically introduced with some very Tanzanian characteristics. For health insurances, a characteristic feature

was the way in which a policy coalition of bureaucrats and development partners framed reforms as a way for the ruling party to live up to one of its core priorities since independence, namely improved and, eventually, universal access to health services, while at the same time improving the efficiency of the sector through the introduction of fees and insurances. The latter were also seen as a way to mobilise additional funds for the sector.

(Pedersen \& Jacob, 2018, p. 4)

In general, the idea of universal access to social services - a prominent feature of the Ujamaa ideology has re-emerged among ruling politicians in the 2000s, especially in the wake of the hardship brought about by the liberalizing economic reforms of the 1980s. This can be seen in the Vision 2025 development programme, which heralded the reintroduction of universal primary and secondary school education which has also spread to the health sector (Pedersen \& Jacob, 2018, p. 12). The National Health Finance Strategy for the period 2015-2020 proposes a single national health insurance (SNHI) program to be managed by the NHIF, which will be tasked with strengthening the iCHF/TIKA in order to reach low-income people and the informal sector. The Parliament was expected to pass SNHI legislation in 2017 (Wang et al., 2018); however, the law has not yet been approved. The interim plan while waiting for the SNHI is to have 
two coexisting schemes: the NHIF aimed at covering the formal sector and the iCHF intended to cover the informal sector and rural households (Lee, Tarimo \& Dutta, 2018). According to Pedersen and Jacob (2018), so far, however, the route taken by the ruling party has been focused more on improving public health infrastructure than health insurances. In addition, even though reforms in health insurance have been pursued, the single mandatory national health insurance heavily pushed by development agencies has so far not materialized.

In summing up, despite their different economic histories, it is clear that, when it comes to social protection, Kenya and Tanzania have similar experiences and trajectories, with both countries currently seeing a very gradual shift from the more residual end towards the more universal end of the social protection spectrum. In both countries, the limited informal worker uptake of formal social protection schemes is linked to issues such as the cost burden and lack of information on the different options. In Tanzania, the iCHF, which is a step towards the roll-out of Universal health insurance, is carried out at the local government level in order to acclimatize the population to the importance of having health insurance. Eventually, after merging the NHIF, iCHF, and NSSF, Tanzania will have a SNHI managed by the NHIF. Thus, although universal health coverage has become a major policy priority in Tanzania, progress on this key aspect of the SDGs is further ahead in Kenya where 2020 saw universal health insurance pilot programs being carried out in four counties. Similarly, Kenya's universal pension scheme Inua Jamii Senior Citizens launched in 2018 is fully government funded, whereas Tanzania's VSRS, also from 2018, as the name indicates relies on contributions from informal workers and their (often non-existent) employer, as such limiting its effectiveness and sustainability. In both countries, it remains to be seen whether the progress towards more universal models of social protection will be stalled or even reversed with the ongoing COVID-19 crisis.

\section{Notes}

1 At the time of writing (end of 2020), the Kenyan government was reviewing the NSPP.

2 Wanyama and McCord (2017) look at the role of Kenya's political settlement in the adoption and promotion of social protection.

3 The KSPSR (2017) calls for further analysis to determine how the contributory schemes can include a higher proportion of people working in the informal economy and whether this would require further changes in legislation.

4 The concept of tupa' is an abstraction of the word 'usitupe' which means "do not throw away".

5 As for salaried employees, contributions are compulsory, with premiums calculated on a graduated scale (between KES 150-1,700/USD 1-16) based on the employees' income and subtracted directly from the payroll.

6 However, it is estimated that only around 4 million NHIF members (out of the 6.2 million) are consistent with their payments (Waweru, 2017). Aside from inactive membership, the NHIF faces a number of other challenges, including reimbursement policies, which have encouraged longer stays in hospitals, the increase in the value of claims, an uneven distribution of payments in different categories of hospitals, and reimbursements that are skewed in favour of private hospitals and nursing homes 
rather than government or mission facilities. Finally, there are also administrative inefficiencies that have contributed to high overhead costs.

7 Mwaura et al. (2015) estimate that private, microfinance and community-based health insurance cover 2 percent of the population.

8 Another strategy for reaching informal workers is the Health Insurance Subsidy Programme (HISP) which is enabling the members of the CT-OVC (Cash Transfer for Orphans and Vulnerable Children) and OPCT schemes to access the NHIF. A 'block' premium is paid by the government to the NHIF corresponding to that payable by the minimum-rate voluntary contributors. This arrangement has been pre-trialled for a limited number of households, with external donor support. However, no information is available on whether assessments have been made of the long-term financial sustainability of this arrangement.

9 If a member loses his/her job either by being fired or retrenched, then that person receives 33 percent of the equivalent of the last salary for a period of six months ('unemployment benefit') and waits for up to two years during a probation period after which it is possible to request withdrawing the benefits and be shifted from the mandatory to a voluntary-based scheme where the applicant pays his or her own benefits.

10 The proposed new policy has, at the time of writing (early 2021), not yet been submitted to cabinet for approval, and there is no official explanation from the government. Matters have been complicated by the movement of government staff from Dar es Salaam to the new capital Dodoma and the dissolving of the SSRA. Whilst official government sources (directorate of social protection in the Ministry of labour) informed that the Trade Union Congress of Tanzania (TUCTA) was involved in the formulation of the policy, TUCTA claims that their inputs were sought after the formulation of the document thus questioning whether their opinions really mattered at that juncture (interview with the former Secretary General of TUCTA).

11 The total registered number of NSSF members was 247,000 in 2020 yet counting only 11,000 active members.

12 Besides the NSSF, the public pensions schemes included the Parastatal Pensions Fund (PPF), the Public Service Pensions Fund (PSPF), the Government Employees' Provident Fund (GEPF), and the Local Authorities' Pensions Fund (LAPF); however, with the PSSSF Act in 2018, all of these were dissolved and combined into one general fund to cater for the public sector.

13 The criteria that one has to contribute for 180 consecutive months ( 15 years) to be eligible for pension under the current NSSF pension scheme makes it a very poor fit with the reality of most informal traders (Riisgaard, 2020).

14 See Pedersen and Jacob (2018) for a detailed account and analysis of the introduction and expansion of health insurance schemes in Tanzania.

15 As for NHIF contribution rates by formal sector workers, these are fixed at 6 percent of the total salary, split equally between the employer and employee.

16 Pedersen and Jacob (2018) also note that figures on health insurance coverage are uncertain as they vary for similar time-periods in different documents. For instance, Lee, Tarimo, and Dutta (2016) report 20 percent coverage for 2014/2015.

17 While 60 percent of health insurance schemes belong to private commercial companies, they cover a very small part of the population. Among the most prominent are AAR, Jubilee, Resolution, and Strategis.

\section{References}

Ackson, T. \& Masabo, J. (2013) Social protection for the informal sector in Tanzania. Available from: http://www.saspen.org/conferences/informal2013/Paper_AcksonMasabo_FES-SASPEN-16SEP2013-INT-CONF-SP4IE.pdf. 
Devereux, S. \& Sabates-Wheeler, R. (2004) Transformative social protection. IDS Working Paper 232. Brighton, Institute of Development Studies.

ILO (2012) ILO recommendation 202: Social protection floors. International Labour Organization.Geneva,InternationalLabourOffice.Availablefrom:https://www.ilo.org/ dyn/normlex/en/f?p=NORMLEXPUB:12100:0::NO::P12100_ILO_CODE:R202.

ILO (2015) ILO recommendation 204: Transition from the informal to the formal economy. International Labour Organization. Geneva, International Labour Office. Available from: https://www.ilo.org/dyn/normlex/en/f?p=NORMLEXPUB: 12100:0::NO::P12100_ILO_CODE:R204.

Kabare, K. (2018) The Mbao pension plan: Savings for the informal-sector. Development pathways. Working Paper: October 2018. Nairobi, Kenya.

KNBS (2019) Economic survey 2019. Nairobi, Kenya, Kenya National Bureau of Statistics.

KSPSR (2012) Kenya social protection sector review 2012. Nairobi, Kenya, Ministry of Labour and Social Protection, State Department for Social Protection.

KSPSR (2017) Kenya social protection sector review 2017. Nairobi, Kenya, Ministry of Labour and Social Protection, State Department for Social Protection.

Lee, B., Tarimo, K. \& Dutta, A. (2018) Tanzania's improved community health fund: An analysis of scale-up plans and design. Health Policy Plus. Washington D.C., Palladium.

Mbekeani, K. (2009) Health sector reforms: Tanzania's health policy strategy to increase access to care and improve health. Medicine and Law: The World Association for Medical Law. 28 (1), 167-179.

Mills, A., Ally, M., Goudge, J., Gyapong, J. \& Mtei, G. (2012) Progress towards universal coverage: The health systems of Ghana, South Africa and Tanzania. Health Policy and Planning. 27 (1), 4-12.

Mushi, L. \& Millanzi, P. (2019) Health insurance for informal workers: What is hindering uptake? Perspectives from female food vendors in Kinondoni District, Tanzania. East African Journal of Applied Health Monitoring and Evaluation. 3, 1-7.

Mwaura, R.N., Barasa, E., Ramana, G.N.V., Coarasa, J. \& Rogo, K. (2015) The path to universal health coverage in Kenya: Repositioning the role of the National Hospital Insurance Fund. Washington, D.C., World Bank.

NSPF (2008) Ministry of finance and economic affairs, poverty eradication and empowerment division, Dar es Salaam. The United Republic of Tanzania.

NSPP (2003) National social protection policy. Tanzania. Available from: http://www. tccia.com/tccia/wp-content/uploads/legal/policy/socialsecuritypolicy.pdf.

NSPP (2011) Kenya national social protection policy. Ministry of Gender, Children, and Social Development, Kenya.

NSSF (2018) National social security fund reports. Compliance and Collection 20142018. Tanzania, National Social Security Fund.

Okungu, V.R. \& McIntyre, D. (2019) Does the informal sector in Kenya have financial potential to sustainably prepay for health care? Implications for financing universal health coverage in low-income settings, health systems \& reform. Health Systems \& Reform. 5 (2), 145-157.

Pedersen, R.H. \& Jacob, T. (2018) Social protection in an electorally competitive environment (2): The politics of health insurance in Tanzania: ESID Working Paper 110. Manchester, UK, The Effective States and Inclusive Development (ESID) Research Centre.

Prabhakaran, S. \& Dutta, A. (2017) Actuarial study of the proposed single national health insurance scheme in Tanzania: A summary brief. Health Policy Plus. Washington D.C., Palladium. 
Riisgaard, L. (2020) Worker Organisation and Social Protection amongst Informal Petty Traders in Tanzania. (4 ed.) Roskilde Universitet. CAE Working Paper No. 2020:4.

ROK (2020) Joint communique: Health sector inter-governmental forum on Universal Health Coverage (UHC), Sarova Whitesands Hotel, Mombasa, October 30, 2020. Mombasa, Republic of Kenya.

Rwegoshora, H.M.M. (2016) Social security challenges in Tanzania: Transforming the present - protecting the future. Dar es Salaam, Mkuki na Nyota.

SSL (2012) The social security laws (amendments) act, 5/2012. International Labour Organization. Geneva, International Labour Office. Available from: https://www.ilo. org/dyn/natlex/natlex4.detail?\&p_isn=94062.

Wang, H., Juma, M.A., Rosemberg, N. \& Ulisubisya, M.M. (2018) Progressive pathway to universal health coverage in Tanzania: A call for preferential resource allocation targeting the poor. Health Systems \& Reform. 4 (4), 279-283.

Wanyama, F.O. \& McCord, A.G. (2017) The politics of scaling up social protection in Kenya: ESID Working Paper 87. Manchester, UK, The Effective States and Inclusive Development (ESID) Research Centre.

Waweru, M. (2017) 12mn people in informal sector yet to register for NHIF. Capital News. Available from: https://www.capitalfm.co.ke/news/2017/01/12mn-peopleinformal-sector-yet-register-nhif/ [Accessed 6 March 2021]. 